\title{
MODOS DE SUBJETIVAÇÃO DOCENTE: A PARTIR DE UMA EDUCAÇÃO SEXUAL “ALÉM DO BIOLÓGICO”*
}

Elaine de Jesus Souza

Claudiene Santos

\section{Introdução}

Um currículo constrói modos de subjetivação a partir de posições discursivas que constituem os sujeitos interpelados por um conjunto de enunciados, práticas pedagógicas e saberes acerca de sexualidade e gênero, (re)compondo um "jeito" de tornar-se educador/a. Na formação docente em Biologia, dispositivos de sexualidade e de gênero acionam um campo heterogêneo de discursos para funcionar, regular a vida ao produzir modos de subjetivação e/ou sujeição atravessados por relações de poder-saber. Esse raciocínio incita diversos questionamentos que indicam novos percursos investigativos: que modos de subjetivação docente são (re)produzidos no currículo de licenciatura em Biologia a partir das temáticas sexualidade e gênero? Ou dito de outra forma: que modos de subjetivação são postos em cena a partir da Educação Sexual que toma corpo nesse currículo e reflete na formação docente? Como esses "sujeitos docentes" são interpelados a partir de práticas culturais propostas na Educação Sexual?

Nessa perspectiva, tais questionamentos se multiplica(ra)m a partir da incorporação de uma Educação Sexual "além do biológico", assumidamente política e socioculturalmente relevante, nos currículos de Biologia de uma universidade pública brasileira. Essa Educação Sexual vem instigando novos olhares, possibilidades e múltiplas histórias de vida de discentes e/ou docentes que se engajam na (re)construção de processos de ensino e aprendizagem acerca das temáticas sexualidade, corpo e gênero. Desse modo, destacamos a principal questão norteadora deste estudo: que modos de subjetivação (e/ou de governamentalidade) são (re)produzidos a partir da Educação Sexual incorporada na formação docente em Biologia?

"DOI - 10.29388/978-65-86678-66-6-f.73-90 


\section{Entrelaçando conceitos acerca da educação sexual}

Nos campos de sexualidade e gênero, não existe um discurso unitário, mas distintos conjuntos discursivos que atravessam a Educação Sexual no currículo de Biologia. Entretanto, tais discursos não estão isentos de deslocamentos conforme o contexto histórico e sociocultural, sendo possível desconstruí-los por meio de estratégias que denunciem os jogos de poder imbricados em sua manutenção. Nessa ótica, a Educação Sexual constitui um sistema político transdisciplinar que pode tanto manter discursos normativos e excludentes alicerçados na díade poder-saber que compõem a governamentalidade, quanto transformá-los a partir de modos de subjetivação favoráveis à multiplicidade que permeia sexualidade, gênero e outras dimensões da vida.

Foucault (2014) argumenta que o termo "sexualidade" surgiu tardiamente, no início do século XIX, e o emprego da palavra foi estabelecido a partir de outros fenômenos, como o desenvolvimento de diversos campos de conhecimentos que englobaram tanto os mecanismos biológicos da reprodução como as diferenças individuais ou sociais do comportamento; a implantação de um conjunto de normas (tradicionais e novas) apoiadas em instituições religiosas, pedagógicas, médicas e judiciárias; e as transformações no modo como os sujeitos dão sentido a suas condutas, seus deveres, prazeres e sentimentos. Nas sociedades ocidentais modernas, foi sendo construída a experiência de reconhecer-se como sujeito de uma "sexualidade", que embora ainda se articulasse num sistema de normas e coerções, começava a expandir esse conceito para campos de conhecimentos diversos. Assim, a correlação entre cultura, campos de poder-saber, normatividades e identidades delineou o projeto de uma história da sexualidade enquanto experiência.

Foucault (2014) discorre sobre a cesura entre a sexualidade masculina e feminina, destacando que os aphrodisia referentes aos "atos, gestos e contatos que proporcionam uma certa forma de prazer" (FOUCAULT, 2014, p. 50) foram pensados como uma ação envolvendo dois atores, cada um com "papéis" específicos, um exercendo a ação e outro "recebendo-a". A experiência de sexualidade simbolizava, no século XIX, um contexto histórico "[...] em que cesura fundamental opõe o masculino e o feminino, a feminilidade do homem é percebida na transgressão efetiva ou virtual de seu papel sexual." (FOUCAULT, 2014, p. 101). Embora não tenha empregado o 
termo "gênero", as teorizações foucaultianas incitam pensar esse conceito também como experiência e constructo sociocultural.

Jorge Larrosa (2011, p. 42) destaca que "[...] ao estudar historicamente a sexualidade do ponto de vista da experiência, Foucault aponta diretamente contra qualquer realismo ou essencialismo do eu, da pessoa humana ou do sujeito." Mesmo sem mencionar o conceito de gênero, as teorizações foucaultianas tornam-se úteis para pensar esse campo, ao relatar as relações conjugais, o monopólio sexual e os usos dos prazeres compartilhados, evidenciando as desigualdades entre homens e mulheres construídas histórica e socioculturalmente, a partir de "obrigações conjugais", noção essencialista de "papéis sexuais" e regime dos prazeres sexuais, que desencadeavam relações de poder assimétricas e sustentavam hierarquizações a fim de manter uma suposta superioridade masculina.

Para Haraway (1995), o conceito de gênero pressupõe problematizar o determinismo que costuma alicerçar descrições biológicas acerca de sexo e corpo para reforçar binarismos e uma noção inatista. Em contraponto, a maioria dos movimentos feministas compreende gênero como diferença localizada no âmbito histórico, sociocultural, simbólico e político. Nessa visão, gênero não constitui algo inerente ao corpo e ao sexo biológico, mas uma dimensão que recebe inscrições sociais, inclusive provenientes de discursos biológicos. Scott (2012) acrescenta que gênero continua sendo uma ferramenta teórico-analítica útil, principalmente, porque possibilita pensar as construções socioculturais em torno de masculinidades, feminilidades e outros modos de tornar-se sujeito para além da noção de "papéis sexuais", logo, embora incluam algumas diferenças sexuais, não se restringem a estas. Portanto, esse conceito permite problematizar o modo como distintas sociedades, culturas, histórias e políticas disputam significados e definições de masculinos e femininos (LOURO, 1997; MEYER, 2004; SCOTT, 2012).

Inspirado em Foucault, Larrosa (2011) ressalta que os modos de subjetivação englobam experiências de si marcadas por discursos que fazem circular relações de poder. O 'ver-se', 'expressar-se' e 'julgar-se' representam modos de subjetividade que podem tanto servir para alicerçar normatizações quanto para problematizar verdades, ao admitir a contingência que permeia distintos campos discursivos, inclusive o currículo de Biologia, possibilitando ensaiar novas formas de "enxergar" a si e ao outro. Tais modos de subjetivação estariam relacionados a 'olhar' as mudanças e/ou movimentos curriculares para reconhecer a instabilidade das questões de sexua- 
lidade e gênero. "Se não conseguimos ver essa mudança ou movimento é porque há algo impedindo e nos levando a ver fixidez, finalização, fechamento" (PARAÍsO, 2018, p. 28).

O currículo constitui um artefato cultural, logo vai além de aspectos conteudistas e disciplinares que compõem a atividade escolar (e acadêmica), pois engloba um conjunto articulado e normatizado de saberes e práticas interpelados pela cultura, que produz identidades e diferenças disseminadas por meio de discursos alicerçados em relações de poder (COSTA, 2005; SILVA, 2015; PARAÍSO, 2010; VEIGA-NETO, 2005). Assim, o currículo possibilita incorporar pedagogias e artefatos culturais (como filmes, novelas, músicas, etc.) que provocam aprendizados e (des)construções nos modos de "tornar-se sujeito". "[...] Tal como a educação, as outras instâncias culturais também são pedagógicas, também têm uma "pedagogia", também ensinam alguma coisa. Tanto a educação quanto a cultura em geral estão envolvidas em processos de transformação da identidade e da subjetividade. [...]" (SILVA, 2015, p.139).

Ao entender o currículo e a Educação Sexual como produtos e produtores de subjetividades, cabe salientar a "[...] subjetividade entendida como o conjunto de processos de subjetivação aos quais os indivíduos foram submetidos ou que aplicaram com relação a si mesmos. [...]" (FOUCAULT, 2016, p.255). Foucault (1995, p. 235) argumentava que "[...] há dois significados para a palavra sujeito: sujeito a alguém pelo controle e dependência, e preso à sua própria identidade por uma consciência ou autoconhecimento. Ambos sugerem uma forma de poder que subjuga e torna sujeito a." Nesse rumo, Foucault (2010, p.225) ressalta o conceito de governamentalidade como:

[...] um campo estratégico de relações de poder, no sentido mais amplo do termo, e não meramente político, entendida pois como um campo estratégico de relações de poder no que elas têm de móvel, transformável, reversível -, então, a reflexão sobre a noção de governamentalidade, penso eu, não pode deixar de passar, teórica e praticamente, pelo âmbito de um sujeito que seria definido pela relação de si para consigo [...] (FOUCAULT, 2010, p.225).

Nesse sentido, outro conceito relevante é o de interpelação, que se refere à forma como os indivíduos adotam distintas posições de sujeito sendo direcionados por meio de discursos a assumir determinada/s identida- 
de/s (WOODWARD, 2014). Ou seja, a interpelação "se dá também no nível das práticas não discursivas; e, dado que sobre essas práticas sempre circulam discursos que a elas se referem, há uma relação complexa entre as práticas (discursivas e não discursivas) que interpelam cada indivíduo" (VEIGA-NETO, 2004, p. 58).

A Educação (Sexual) pressupõe múltiplas formas de produzir sujeitos de acordo com saberes e práticas sociais, ou seja, em geral as necessidades, exigências e aspirações de uma sociedade ditam os saberes que possibilitam a formação dos sujeitos. Como a Educação resulta e reflete as práticas sociais, não seria viável seguir uma única direção, visto que a educação é interpelada por distintos interesses que fazem emergir pedagogias plurais para conduzir o processo de ensino e aprendizagem e a produção dos sujeitos (CAMOZZATO; COSTA, 2013).

Nesse olhar, uma Educação Sexual "além do biológico" parece significativa não somente no currículo de Biologia, mas em distintos espaços educativos, sobretudo ao ser incorporada como uma invenção cultural que resulta de múltiplas histórias e possibilidades. Afinal, "um currículo pode estar feito da mesma matéria dos sonhos, nos quais tudo é possibilidade?" (PARAísO, 2018, p. 49). A construção de qualquer campo de saber advém de discursos que produzem uma multiplicidade de saberes, práticas, vivências e representações em torno de sexualidade, gênero e, assim nos interpelam e constituem enquanto sujeitos transitórios e contingentes nessa cultura cambiante.

\section{Percurso metodológico}

Os percursos teórico-metodológicos possibilitaram colher pistas acerca dos modos de subjetivação docente a partir da Educação Sexual incorporada no currículo de Biologia da Universidade Federal de Sergipe (UFS). O exercício de problematização instigou-nos a (re)inventar os modos de examinar discursos permeados por relações de poder, para Foucault (2017a), aprender a problematizar significa realizar um movimento de análise crítica, observando como foram construídas diferentes soluções acerca de um problema e/ou uma temática.

Os procedimentos investigativos envolveram duas etapas de pesquisa: a primeira com a organização de grupos focais e, a segunda etapa a partir de questionários aplicados a estudantes e participantes do I Seminá- 
rio - Ditos e não ditos sobre Corpo, Gênero e Sexualidade no Ensino de Ciências e Biologia, referente à disciplina Corpo, Gênero e Sexualidade (CGS).

Os grupos focais foram organizados em três encontros semanais com sete participantes (quatro recém-formados/as e três formandos/as, que já haviam cursado as disciplinas Corpo, Gênero e Sexualidade (CGS) e Perspectivas culturais no Ensino de Biologia e Educação (PCEBE), da UFS. Além da primeira autora atuar como moderadora, houve a colaboração de dois observadores, que auxiliaram na condução dos grupos, nas anotações, gravação e filmagem das reuniões. Para que os grupos focais possibilitassem uma interação entre os/as participantes, houve o planejamento de atividades que incluíram a discussão de alguns artefatos culturais, tais como músicas, imagens, vídeos, visando explorar discursos acerca de sexualidade e gênero, que permeiam a Educação Sexual na formação docente em Biologia.

O Seminário ocorreu em 8 encontros, embasados por artigos e vídeos com os temas e, posterior elaboração de portfólios reflexivos: Corpo, Gênero e Sexualidade em livros didáticos; na Base Curricular Nacional Comum (BNCC), nas (d)eficiências; Racismo, Interseccionalidade, Diversidade Sexual no Ensino de Ciências e Biologia; Gênero e Ciência: protagonismo feminino nas Ciências Naturais; Violências contra mulheres, jovens, idosas/os e/ou LGBTQIA+ e a Educação Sexual e as problematizações para "além do biológico".

Como procedimento analítico para problematizar os discursos no campo da Educação Sexual, adotamos a análise foucaultiana do discurso. Para Rosa Fischer (2001), a teorização foucaultiana sobre o discurso sugere aos/as pesquisadores/as um modo de investigar não o que "está por trás" dos textos e documentos, mas "as coisas ditas". Logo, a preocupação não é o que se queria dizer com aquilo, mas, descrever quais são as condições de existência de um determinado discurso (e seu conjunto de enunciados), levando em consideração o contexto histórico e sociocultural em que os discursos foram produzidos. Foucault (2015) argumenta que a análise do enunciado não pretende ser exaustiva da linguagem, mas, corresponde a um nível peculiar de descrição que envolve relação com um domínio de objetos, jogo de posições de sujeito; campo de coexistência e materialidade repetível. 


\section{Educação sexual em currículos de Biologia: modos de subjetivação docente (im)possíveis}

$\mathrm{Na}$ análise dos discursos sobre a Educação Sexual nos currículos de Biologia da UFS, evidenciamos a presença marcante de relações de podersaber que balizam (des)aprendizados, limites e possibilidades nas práticas docentes sobre sexualidade e gênero. Nesse rumo, os modos de subjetivação (im)possíveis nesses artefatos culturais enfatizaram estratégias de produção e/ou materialização de discursos acerca da Educação Sexual como um campo transdisciplinar, múltiplo e contingente. Tal exercício analítico pressupõe a tentativa de capturar enunciados acerca da Educação Sexual incorporada nesse currículo de Biologia e a (re)produção de modos de subjetivação docente.

Quadro 1 - 1․ Encontro do Grupo focal com (futuros/as) biólogos/as (DBI/ UFS)

Ruan: [...] a professora mandava a gente trabalhar muito a questão de auto se reconhecer, escrever como foi o dia, é se gostou da aula, do que mais gosta, do que menos gostou na aula, então a gente tinha uma opinião da aula, entendeu? Não só ficava centrada nela, a gente discutia isso, ela trazia muito a questão dos sentimentos, que é muito deixado de lado nas aulas dos outros professores a gente trabalha muito só conteúdo, conteúdo, conteúdo e o professor não se importa com as nossas características individuais, as nossas peculiaridades, e ela se importava, eu gostava muito disso. [...]

Emilly: [...] eu lembrei que a disciplina "Instrumentação para o ensino de Ciências e Biologia", a gente trabalhou com esse tema, a disciplina foi dividida em um trabalho prático onde a turma ficou dividida em dois grupos e o nosso grupo incialmente ficou com essa parte da Educação Sexual. [...] o trabalho foi esse a gente levou uma caixinha dessa com algumas curiosidades e alguns dilemas e um deles, dentro da caixinha tinha a foto do filho de Will Smith com uma roupa de muIher e a gente levou pra discussão na sala de aula [...]

Bianca: [...] a gente vai percebendo que o assunto é importante, só que vai variar muito de quem está aplicando, de quem está à frente pra poder fazer com que a gente pense nisso, porque isso é importante!

Fonte: Primeira Autora (21/06/17)

A partir dos ditos acima, evidenciamos a relevância de uma educação afetiva que considere as questões socioemocionais dos/as licenciandos/as, em consonância Meyer (2009, p.222) aponta a educação 
como "[...] o conjunto de processos através do qual indivíduos são transformados ou se transformam em sujeitos de uma cultura". Nessa direção, para construir processos formativos que oportunizem o autoconhecimento e a empatia, os saberes e as práticas docentes precisariam ultrapassar os limites dos conteúdos disciplinares. Desse modo, a Educação Sexual, por meio de abordagens histórica, sociocultural, afetiva, política, semântica (FURLA$\mathrm{NI}, 2005)$ possibilitaria ir "além do biológico".

Para Larrosa (2011), as práticas de formação docente deveriam incitar futuros/as professores/as a refletir sobre e problematizar as temáticas socioculturais, visando uma mudança no modo como construíram suas identidades pessoais e profissionais. Dessa forma, tenta-se transformar não somente o/a docente como profissional, mas instituir por meio de saberes e práticas uma transformação pessoal do/a educador/a, o que culmina com a produção de modos de subjetivação docente. "Uma formação docente costuma ser constituída [...] como um espaço no qual se aprende a "pensar" e a "argumentar" sobre questões educativas de determinada maneira." (LARROSA, 2011, p. 50). Nessa perspectiva, os/as futuros/as professores/as vão "construindo a ideia da educação em relação com uma ideia do social, do político, do cultural [...]" (LARROSA, 2011, p. 50) e do subjetivo.

Quadro 2 - 2을 Encontro do Grupo focal com (futuros/as) biólogos/as (DBI/ UFS)

Pâmela: Você sempre pergunta o que as disciplinas mudaram na nossa visão da sexualidade, pra mim não foi nem tanto as disciplinas, foi entrar na UFS [...] aqui eu vi uma diversidade de pessoas, de jeitos, de comportamentos e sim tinham aquelas pessoas que julgavam as outras por mostrarem quem você é. [...] Então, tipo a mente abriu: não é só aquilo, não é só o preto e branco, existem várias cores entre o meu mundo, então chocou com minha realidade, chocou com o que eu aprendi na minha casa, na minha escola, e as disciplinas serviram de apoio, no sentido de eu vejo, eu sei que tem, mas o que é? Como eu vou lidar com isso, como eu vou lidar com isso na sala de aula? As disciplinas serviram pra isso, quebraram preconceitos meus que eu tinha e abriram tipo um novo mundo, mas a minha entrada aqui na UFS foi o principal pra ver que tinha alguma coisa além do branco e do preto, as disciplinas serviram de apoio, mas a entrada aqui foi o que abriu esse mundo pra mim.

Bianca: [...] Aí quando você entra na Universidade você se depara com a liberdade [...] é onde você começa a ver a sua transição, começa realmente mostrar aquilo que você é [...]

Fonte: Primeira Autora (27/06/17) 
Tais enunciados evidenciam que a Universidade constitui um espaço formativo que engloba uma diversidade de vivências e identidades/diferenças implicadas no processo de construção da profissão docente. Nesse contexto, em entrevista a Viviane Mosé para o livro "A escola e os desafios contemporâneos", José Pacheco ao falar sobre "a Escola da Ponte e o eixo autonomia/responsabilidade", ressalta: "[...] O que fica nos jovens professores não é o que eles ouvem, o que supostamente lhes ensinam, mas o que vivem na universidade. O modo como o professor aprende será o modo como professor ensinará." (MOSÉ, 2013, p.290).

Contudo, para Henri Giroux (2013), a universidade, com suas políticas e diretrizes curriculares para formação docente, tem sido relacionada a discursos científicos que reforçam a cultura tradicional e ocidental. Tal cultura excludente tem marginalizado as múltiplas vozes, narrativas e histórias de indivíduos e grupos socioculturais e políticos subordinados. Como uma Educação Sexual em parceria com os movimentos sociais de Lésbicas, Gays, Bissexuais e Transgêneros (LGBT), feministas, de políticas afirmativas, entre outros, poderia problematizar o modo como esse conhecimento acadêmico, frequentemente utilizado para silenciar docentes e estudantes, tem sido disseminado nas escolas? Que discursos são disseminados na universidade pública que educa professores/as através de um currículo tradicional? Que saberes e práticas são legitimados nos espaços escolares para a abordagem de uma Educação Sexual? Esses questionamentos permearam (e ainda permeiam) o processo de historicização e desenvolvimento da Educação Sexual nos espaços educacionais, por meio de abordagens sobre sexualidade, corpo e gênero.

Para Foucault (2017a, p. 233), a sexualidade seria analisada "como um modo de experiência historicamente singular, no qual o sujeito é objetivado para ele próprio e para os outros, através de certos procedimentos precisos de "governo". Nesse contexto, a sexualidade envolveria uma "[...] história da "subjetividade", se entendermos essa palavra como a maneira pela qual o sujeito faz a experiência de si mesmo em um jogo de verdade, no qual ele se relaciona consigo mesmo." (FOUCAULT, 2017a, p. 230). Desse modo, objetivação e subjetivação são interdependentes e relacionadas a "jogos de verdade" (FOUCAULT, 2017a) que marcaram a história da sexualidade e, portanto, constituem a Educação Sexual que também abrange a dimensão de gênero.

Deleuze (2013, p.135), ao abordar sobre Foucault e suas teorizações, sobretudo, seu interesse em investigar os modos de subjetivação 
como "um pouco de possível, senão eu sufoco...", levanta o seguinte questionamento: "em que lugares e como se produzem novas subjetividades?" (p.146). Não com a intenção de apontar respostas prontas, mas provocar problematizações em torno de dimensões e relações sociais, como sexualidade, que (re)produzem processos de subjetivação diversos passíveis de poder e resistência. Ainda relata três encontros de Foucault com Nietzsche, primeiro ao entender o poder como potência e, portanto, destoante de violência; segundo, ao destacar as relações de forças que constituem os seres humanos; e o terceiro se refere, justamente, aos processos de subjetivação como a criação de modos de existência, ou seja, a invenção de novas possibilidades de vida (DELEUZE, 2013, p.151).

Nessa direção, as disciplinas CGS e PCEBE apontam novos olhares para o currículo e a formação docente em Biologia, a partir da incorporação das temáticas socioculturais da Educação Sexual, vislumbramos os limites e as possibilidades da vida humana, principalmente nas dimensões de sexualidade e gênero, a saber:

Quadro 3 - 3ํ Encontro do Grupo focal com (futuros/as) biólogos/as (DBI/ UFS)

Moderadora: [...] como vocês avaliam os efeitos da formação docente, do currí-
culo de biologia acerca de sexualidade, gênero e educação sexual? Uma avalia-
ção de modo geral do currículo de biologia com relação a essas temáticas, vocês
apontariam sugestões?

Bianca: [...] Teria que ter mais disciplinas como essas, voltadas pra essas temáticas [...] Ou seja, já teria Perspectivas, Corpo, gênero e sexualidade, entraria Didática I e II que dá pra trabalhar com isso e Instrumentação, já teriam cinco disciplinas que podem trabalhar com isso. [...]

Pâmela: Eu acho o que Bianca falou interessante, não é o suficiente isso é fato, mas como eu acho que foi Ruan que já falou, que a gente tá a frente de outras licenciaturas, sim a gente tá, mas não é o suficiente. E questão de tipo como a gente tá lidando com isso? [...] a gente vê a teoria e a prática? Entendeu?

Pietra: [...] o nosso currículo realmente ele está à frente em relação a outros cursos falando sobre essa questão da sexualidade, [...] só que realmente falta, falta muito, a gente vê basicamente isso em Corpo, gênero e sexualidade [...]

Will: [...] eu creio que não foi fácil implantar uma disciplina de Corpo, gênero e sexualidade no departamento [...] e bom foi um trabalho que tá gerando frutos legais, tá desconstruindo muita coisa, tá contribuindo muito pra formação dos graduandos.

Pâmela: No curso todo de licenciatura fala muito de interdisciplinaridade, que as disciplinas têm que se juntar, tem que fazer, só que aqui na Universidade a gen- 
te não vê isso, como a gente vai chegar na escola e vamos fazer, juntar todas as disciplinas pra ser uma coisa só, pra todo mundo aprender mais, se a gente não aprende isso, é difícil!

Fonte: Primeira Autora (05/07/17)

Ao enfatizarem que o currículo de Biologia da UFS está um passo à frente de outras licenciaturas e/ou universidades em decorrência da inclusão de disciplinas que efetivamente abordam sexualidade e gênero, os/as futuros/as docentes entram numa discussão sobre a importância de "conectar disciplinas" e, seguindo esse raciocínio, a fala de Pâmela destaca a questão da "interdisciplinaridade" que ronda a universidade e a escola. Nessa ótica, é importante problematizar o conceito de interdisciplinaridade, pois ao compreender a Educação Sexual como um campo transdisciplinar constituído por discursos sobre sexualidade e gênero, significa mais que uma conexão entre diferentes disciplinas e/ou campos de saber. Principalmente, porque essa noção de transdisciplinaridade envolveria um modo de pensar que atravessa, mas não se restringe, as disciplinas, visto que produz saberes e práticas com perspectivas convergentes e/ou divergentes.

Questionamentos vêm à tona quando Pâmela ressalta que, embora no curso de licenciatura em Biologia tenha sido reforçada a necessidade desse movimento interdisciplinar na escola, tal noção não seria 'implementada' na própria Universidade e/ou nesse currículo. A partir desses ditos, é possível capturar e examinar o seguinte enunciado acerca do conceito de interdisciplinaridade que significaria: "juntar todas as disciplinas pra ser uma coisa só, pra todo mundo aprender mais...". Veiga-Neto (2012) acrescenta que, de forma sintética, o movimento pela interdisciplinaridade visa a integração entre os saberes através de novos arranjos curriculares e outros modos de trabalhar os conteúdos disciplinares; além disso numa visão mais distante pressupõe alcançar "a unidade do saber", ou seja, por meio da fusão disciplinar, excluiria a própria noção de disciplinaridade. Esse movimento utiliza metodologias de trabalho pedagógico numa tentativa de recuperação da "totalidade de pensamento", a qual teria sido deixada de lado devido a fragmentação de saberes que a ciência moderna incitou, modificando nossas formas de pensar e ver o mundo.

Em contraponto, o termo transdisciplinaridade abriga múltiplos significados a depender da perspectiva teórica, contudo ao considerar que o prefixo "trans" significa "estar entre e ir além de", bem como a palavra "disciplinaridade" remete ao reconhecimento das especializações de cada disci- 
plina (FLORES; ROCHA FILHO, 2016), admite-se que saberes e práticas extrapolam áreas específicas, a partir de um exercício pedagógico que favoreça transitarem por distintos campos. Para Basarab Nicolescu (1999), em complemento à abordagem disciplinar, a transdisciplinaridade possibilitaria a utilização de disputas entre campos específicos para produzir novos saberes e novas práticas que se articulam entre si. Dessa maneira, "a transdisciplinaridade não busca o domínio de várias disciplinas, mas a abertura de todas elas àquilo que as atravessa e as ultrapassa" (NICOLESCU, 1999, p. 161).

Ademais, destacamos o seguinte enunciado recorrente, de diferentes modos, nas falas de licenciandos/as: "a gente vê a teoria e a prática?", visto que uma perspectiva pós-estruturalista permite "[...] problematizar uma compreensão de currículo pautada na dicotomia teoria/prática, enfatizando que, ao compreendermos o currículo como um artefato cultural, rejeitamos a ideia de que haja dois currículos, um "na teoria", outro "na prática", e assumimos sua indivisibilidade. [...] (DAL'IGNA; KLEIN; MEYER, 2016, p.471).

As práticas pedagógicas numa lógica inter-transdisciplinar constituem um conjunto de ações que favoreceriam modos de ensinar e aprender a partir das relações com os sujeitos e o contexto sociocultural, sobretudo ao assumir a intersubjetividade como essencial em cada ação pedagógica. A partir dessa perspectiva inter-transdisciplinar, a Educação (Sexual) incitaria a superação de oposições binárias, o diálogo e o trabalho coletivo entre docentes e discentes, reconhecimento dos saberes populares e/ou subjugados, assim a integração, cooperação e a valorização das diversidades seriam adotadas nos currículos escolares e acadêmicos, visando transformações decorrentes de aprendizados permanentes, metodologias criativas e uma cultura de compartilhamento (SOUSA; PINHO, 2017).

Sobre práticas docentes inter-transdisciplinares, na disciplina CGS da UFS, os/as discentes foram questionados/as acerca dos aprendizados e desconstruções após as aulas e o ciclo debates no I Seminário Ditos e não ditos sobre Corpo, Gênero e Sexualidade no Ensino de Ciências e Biologia, e destacamos as seguintes enunciações: 
Quadro 4 - Aprendizados de futuros/as docentes (Questionário da disciplina CGS/UFS)

Educação Sexual e as problematizações para "além do biológico".

Palestra extremamente importante para que possamos repensar a Educação Sexual para além das questões biológicas, enxergando-a enquanto potência e como um mecanismo para a desconstrução (e posterior construção) de conceitos sobre corpo, sexualidade, gênero.

Foi uma apresentação muito interessante e que me chamou muito atenção por abordar assuntos vivenciados em minha vida e até mesmo meus medos, como o medo sobre as aulas de educação sexual e a resposta da escola e família sobre tal.

Racismo e Interseccionalidade no Ensino de Ciências e Biologia

Debates importantes para a formação de professores, que encontra uma diversidade de pessoas em sala de aula, a importância da representatividade dentro dos livros didáticos, para que os discentes possam se sentir representados no processo de ensino e aprendizagem.

Diversidade Sexual no Ensino de Ciências e Biologia

Essa foi uma das melhores palestras. Ter a presença de pesquisadores(ras) que estão na luta a fim de extrapolar a biologia higienista que reforça estereótipos e preconceitos é fundamental na construção de docentes humanos.

Violências contra mulheres, jovens, idosas/os e/ou LGBTQIA+

Temática abordada extremamente importante para nós futuros professores, fala de acontecimentos que infelizmente continuarão a ocorrer e precisamos estar preparados, compartilhar experiências é uma excelente fonte de informação e formulação de um pensamento de ação.

Discussões pertinentes sobre todos os tipos de violência, relatos que nos fazem refletir sobre nosso papel como educador. Em como fazer com que nossos alunos aprendam, se muitos passam todos os dias por casos de violência dentro da própria família. [...]

Corpo, Gênero e Sexualidade na Base Curricular Nacional Comum (BNCC)

Corpo Gênero e sexualidade pode ser discutido dentro de qualquer conteúdo da biologia. A questão é como o professor irá discutir. O currículo não impede a discussão de gênero e sexualidade para que possamos trabalhar essas questões de relacionamentos ou comportamentos em todo tempo.

Gênero e Ciência: protagonismo feminino nas Ciências Naturais

Uma apresentação de abrir olhos, pois pude perceber muitos aspectos nos quais não tinha notado ainda. $\mathrm{O}$ fato de saber que as mulheres são minoria na ciência, $\mathrm{e}$ saber que isso já vinha sendo modificado mas não percebia o quão longe ainda estamos de ocupar mais vagas nas ciências. A muito a ser percorrido ainda. [...]

Educação sexual (d)eficiência(s)

Palestra essencial! Estou cursando a disciplina de Libras e percebo a necessidade da institucionalização da disciplina não só na graduação, mas também no ensino 
fundamental e médio, tendo em vista que pessoas surdas estão em todos os espaços e não podemos ser mais um obstáculo na vida delas. O mesmo falo para pessoas cegas ou com qualquer outro tipo de deficiência. $A$ acessibilidade além de ser um direito constitucional deve ser de interesse social.

Fonte: Segunda Autora (2020)

Tais ditos dos/as (futuros/as) docentes, ao ressaltarem a relevância e os aprendizados instigados a partir das discussões de temáticas socioculturais no Seminário de CGS, sinalizam uma ideia do "ir além" de conteúdos disciplinares, que admite diversos sentidos, tais como "percorrer outros caminhos", "seguir em frente", "transgredir", "distanciar-se de algo" e/ou "afastar-se do conhecido", mas sobretudo enfatiza o reconhecimento de que a Educação Sexual consegue "ir além do biológico". Isto é, "ir além" do que discursivamente foi 'inventado' como Biologia, durante muito tempo, vista como um campo de saber encerrado numa redoma científica alicerçada em enunciados da fisiologia, anatomia, evolução, genética, medicina que integrariam um "discurso verdadeiro e universal" sobre distintas questões da vida individual e/ou social, principalmente sobre as temáticas da Educação Sexual.

Além dos conceitos relativos a sexualidade, corpo e gênero, os aprendizados provocados nessa disciplina evidenciam que a desconstrução de preconceitos perpassa por estratégias didático-metodológicas que possibilitem reconhecer as múltiplas identidades/diferenças, portanto "extrapolar a biologia higienista que reforça estereótipos e preconceitos é fundamental na construção de docentes humanos", como destacado nos ditos acima. Em consonância com Mosé (2013), ressaltamos que os currículos escolares e acadêmicos não deveriam se limitar a mera transmissão de conhecimentos em uma visão tecnicista e conteudista, visto que as demandas educacionais contemporâneas acentuam o quanto é fundamental produzir vínculos e relações humanas para nos tornarmos melhores educadores/as, educandos/as, pessoas. Assim, na escola, na universidade e em todos os espaços educativos, precisamos adotar e/ou (re)criar "[...] instrumentos capazes de fazer com que a pessoa aprenda sem perder o humano. O humano é fundamental. [...]" (MOSÉ, 2013, p.146).

Os discursos se deslocam na Educação Sexual desse currículo, reinventando práticas culturais que não se restringem ao nível do que é dito ou pensado pelos/as (futuros/as) docentes, mas provocam uma constante interpelação. Essas práticas culturais interpelativas, não apenas tentam dizer 
ao indivíduo quem ele é, o que deve ser e/ou fazer, mas (re)inventam categorias como sexualidade e gênero, "criam referentes que se constituem como marcadores pelos quais os sujeitos passam a se reconhecer e posicionar." (HENNIGEN; GUARESCHI, 2006, p. 60). Os significados culturais implicados na Educação Sexual não somente produzem "verdades provisórias" como recriam estratégias dinâmicas para questionar e problematizar "o estatuto de verdade" que delimita posições de sujeito. "Nesse sentido, tratase de considerar o sujeito (des)centrado como 'terreno fértil', constituído por uma ampla e variada gama de processos educativos que têm como objetivo aproximar o outro da 'nossa cultura', dos 'nossos modos de ser'." (DORNELLES; DAL'IGNA, 2015, p. 1587). Assim, “[...] esse sujeito não passa de uma invenção cultural, social e histórica, não possuindo nenhuma propriedade essencial e originária." (SILVA, 2015, p. 120).

Tal perspectiva pressupõe uma formação docente que promova a curiosidade, pesquisa, criação, além de competências e habilidades articuladas com a diversidade sociocultural que permeia os distintos espaços educativos, sobretudo a escola e a universidade. Portanto, a educação contemporânea tem como desafio e urgência formar professores/as, pesquisadores/as, autonômos/as e responsáveis, que estimulem o protagonismo estudantil (MOSÉ, 2013) e, a problematização de saberes e práticas socioculturais. Nesse sentido, a Educação Sexual instiga modos de subjetivação docente que abrangem saberes e práticas muito além de uma dimensão conteudista, ao evidenciar o quanto "a vida" deve estar imersa em todo o processo de ensino e aprendizagem. Posto que "[...] Se não houver vida naquilo que aprendemos, então não há educação, formação e muitos menos aprendizagem" (MOSÉ, 2013, p.82).

Que "possamos repensar a Educação Sexual para além das questões biológicas, enxergando-a enquanto potência e como um mecanismo para a desconstrução (e posterior construção) de conceitos sobre corpo, sexualidade e gênero."

\section{Conclusões transitórias...}

Os modos de subjetivação (e/ou de governamento) (re)produzidos no currículo de Biologia da UFS evidenciam uma formação docente que ao incorporar a Educação Sexual como um campo transdisciplinar, desafia os limites de representações essencialistas que focalizam somente em conteú- 
dos disciplinares e deixam de lado aprendizados sobre e para a vida em suas distintas nuances. Ao multiplicar as lentes dos processos de ensino e aprendizagem para enxergar que as vidas humanas constituem-se de múltiplas identidades e diferenças, vislumbramos as possibilidades de currículos que (re)inventam práticas docentes pluralistas, inclusivas e democráticas. Em consonância com modos de subjetivação que se desdobram para além do cuidado de si e dos outros, por meio de estratégias didático-metodológicas e exercícios de problematização, incitando o questionamento de saberes, "verdades absolutas" e relações de poder.

Ainda que a Biologia como "domínio científico" continue (re)produzindo regimes de verdade, enquanto educadores/as ao menos estamos investindo em estratégias para "duvidar do instituído"; a partir de uma perspectiva sociocultural e política da Educação Sexual incorporada nesse currículo que "ousa" ensaiar caminhos para "além do biológico", ou do que se costumava entender por "biológico" (no campo exclusivamente científico), ao reconhecer que a própria Biologia representa "uma construção cultural". Nesse trajeto, sexualidade e gênero atravessam esse campo deixando pegadas por meio de questionamentos, problematizações e (des)construções, quem sabe, assim, menos certezas e prescrições...

\section{Referências}

COSTA, Marisa Vorraber. Currículo e política cultural. In: COSTA, Marisa Vorraber (Org.). O currículo nos limiares do contemporâneo. 4. ed. Rio de Janeiro: DP\&A, 2005. p. 37-67.

DAL'IGNA, Maria Cláudia; KLEIN, Carin; MEYER, Dagmar Estermann. Generificação das práticas curriculares: uma abordagem feminista pós-estruturalista. Currículo sem Fronteiras, v. 16, n. 3, p. 468-487, set./dez. 2016.

DELEUZE, Gilles. Conversações. 3. ed. São Paulo: Ed. 34, 2013.

DORNELLES, Priscila Gomes; DAL'IGNA, Maria Cláudia. Gênero, sexualidade e idade: tramas heteronormativas nas práticas pedagógicas da educação física escolar. Educ. Pesqui., São Paulo, v. 41, n. especial, p. 1585-1599, dez. 2015. 
FOUCAULT, Michel. O sujeito e o poder. In: DREYFUS, Hubert; RABINOW, Paul (Org.). Michel Foucault: uma trajetória filosófica. Rio de Janeiro: Forense Universitária, 1995. p.231-249.

FOUCAULT, Michel. História da Sexualidade 2: o uso dos prazeres. São Paulo: Paz e Terra, 2014.

FOUCAULT, Michel. A Arqueologia do saber. 8. ed. Rio de Janeiro: Forense Universitária, 2015.

FOUCAULT, Michel. Subjetividade e verdade: curso no Collége de France (1980-1981). Tradução Rosemary Costhek Abílio. São Paulo: Editora WMF Martins Fontes, 2016.

FOUCAULT, Michel. Ética, Sexualidade e Política. Organização de Manoel Barros da Motta. 3. ed. Rio de Janeiro: Forense Universitária, 2017a. (Coleção Ditos \& Escritos V).

HARAWAY, Donna. Saberes localizados: a questão da ciência para o feminismo e o privilégio da perspectiva parcial. Cadernos Pagu, Campinas, v. 5, p. 7-41, 1995.

HENNIGEN, Inês; GUARESCHI, Neuza Maria de Fátima. A subjetivação na perspectiva dos estudos culturais e foucaultianos. Psicologia da Educação, São Paulo, v. 23, p. 57-74, 2ㅇ sem. de 2006.

LARROSA, Jorge. Tecnologias do Eu e Educação. In: SILVA, Tomaz Tadeu da (Org.). O sujeito da Educação: estudos foucaultianos. 8. ed. Petrópolis: Vozes, 2011. p. 35-86.

LOURO, Guacira Lopes. Gênero, sexualidade e educação: uma perspectiva pós-estruturalista. Petrópolis: Vozes, 1997.

MEYER, Dagmar Elisabeth Estermann. Teorias e políticas de gênero: fragmentos de histórias e desafios atuais. Revista Brasileira de Enfermagem, Brasília, v. 57, n. 1, p. 13 -18, jan./fev. 2004. 
MOSÉ, Viviane. A escola e os desafios contemporâneos. Rio de Janeiro: Civilização Brasileira, 2013.

PARAÍSO, Marlucy Alves (Org.). Pesquisas sobre currículos e culturas: temas, embates, problemas e possibilidades. Curitiba: Editora CRV, 2010.

PARAÍSO, Marlucy Alves (Org.). Fazer do caos uma estrela dançarina no currículo: invenção política com gênero e sexualidade em tempos do slogan "ideologia de gênero". In: PARAÍsO, Marlucy Alves; SILVA, Maria Carolina da. Pesquisas sobre currículos, gêneros e sexualidades. Belo Horizonte: Mazza Edições, 2018. p. 23-52.

SCOTT, Joan. Os usos e abusos do gênero. Projeto História, São Paulo, n. 45, p. 327-351, dez. 2012.

SILVA, Tomaz Tadeu. Documentos de identidade: uma introdução às teorias do currículo. 3. ed. Belo Horizonte: Autêntica, 2015.

SOUSA, Juliane Gomes de; PINHO, Maria José de. Interdisciplinaridade e transdisciplinaridade Como fundamentos na ação pedagógica: Aproximações teórico-conceituais. Revista Signos, Lajeado, ano 38, n. 2, 2017.

VEIGA-NETO, Alfredo. Currículo e História: uma conexão radical. In: COSTA, Marisa Vorraber (Org.). $O$ currículo nos limiares do contemporâneo. 4. ed. Rio de Janeiro: DP\&A, 2005. p. 93-104. 